\title{
MIGRAÇÃO DE SUPORTE PARA A PRESERVAÇÃO DE ACERVOS FOTOGRÁFICOS: ESTUDO DE CASO NO ARQUIVO FOTOGRÁFICO DO CURSO DE ARQUIVOLOGIA DA UFSM
}

\author{
MIGRATION OF MEDIUM FOR THE PRESERVATION OF \\ PHOTOGRAPHIC COLLETIONS: CASE STUDY IN THE PHOTOGRAPHIC \\ ARCHIVE FROM THE COURSE OF ARQUIVOLOGIA OF UFSM
}

Eliseu dos Santos Lima ${ }^{1}$, Murilo Billig Schäfer² E Carlos Blaya Perez ${ }^{3}$

Recebido em: 16/08/2013

Aprovado em: 14/10/2013

\section{RESUMO}

Os acervos fotográficos preservam os registros de ações realizadas por indivíduos e/ou instituições, permitindo que sua história seja mantida ao longo do tempo como fonte de informação e conhecimento. Desse modo, este estudo refere-se ao acervo fotográfico do Curso de Arquivologia da Universidade Federal de Santa Maria (UFSM), tendo por objetivo estudar a migração do suporte fotográfico tradicional para o digital, visando à sua difusão e preservação. Os objetivos específicos pautaram-se em definir qual a melhor maneira de efetivar a reprodução/migração de suporte - por digitalização ou reprodução fotográfica -, quais as mídias a serem utilizadas para armazenar as cópias de segurança, qual a resolução ideal para o armazenamento das imagens e quais as normas indicadas para a sua descrição. Os resultados do estudo servirão de referência à salvaguarda de registros de arquivos fotográficos e ao seu acesso, seja em meio físico ou digital.

Palavras-chave: Arquivologia; Fotografia; Digitalização; Reprodução Fotográfica; Arquivo Fotográfico.

\section{Introdução}

Assim como os demais tipos de documentos, a fotografia é um importante meio de preservar a memória de determinado órgão ou instituição. E isso só é alcançado quando a instituição se empenha em dispor aos usuários novas

\begin{abstract}
The photographic archives record the actions taken by individuals and/or institutions, allowing your story to be maintained over time as a source of information and knowledge. Thus, this study refers to the photographic collection of the Course of Archival Federal University of Santa Maria (UFSM), aiming to study the migration of traditional photographic media to digital, aiming at the dissemination and preservation. The specific objectives guided in defining how best to effect reproduction/ migration support, either by scanning or photographic reproduction, the media to be used to store the backups, the optimal resolution for image storage, and standards set for its description. The study results provide a reference to safeguarding and access to records of photographic archives in the physical as well as in digital format.

Keywords: Archival; Photography; Scanning; Photo Playback; Photo Archive.
\end{abstract}

formas de acesso e suporte a esse importante tipo documental.

O Curso de Arquivologia da Universidade Federal de Santa Maria, em seus trinta e sete anos de existência, acumulou um acervo fotográfico significativo, tanto no que diz respeito ao conteúdo quanto ao volume das in-

\footnotetext{
${ }^{1}$ Especialista em Gestão em Arquivos pela Universidade Federal de Santa Maria (UFSM), Brasil. Arquivista do Departamento de Gestão Documental da Universidade Federal da Fronteira Sul (UFFS). E-mail: eliseudsl@yahoo.com.br.

${ }^{2}$ Mestre em Patrimônio Cultural pela Universidade Federal de Santa Maria (UFSM). Arquivista do Departamento de Gestão Documental da Universidade Federal da Fronteira Sul (UFFS). E-mail: mbsarquivo@yahoo.com.br.

${ }^{3}$ Doutor em Biblioteconomia y Documentación pela Universidad de Salamanca (USAL), Espanha. Professor do Departamento de Documentação da Universidade Federal de Santa Maria (UFSM). E-mail: carlosblaya@hotmail.com.
} 
formações contidas nas imagens. São registros fotográficos que retratam docentes, discentes, técnicos administrativos e convidados em eventos científicos realizados no Brasil e no exterior.

O acervo fotográfico do Curso conta com, aproximadamente, três mil fotografias, que estão armazenadas em suporte filme, em papel fotográfico e em meio digital, sendo este o suporte que predomina atualmente. Nesse contexto, esta pesquisa teve como objetivo geral estudar a migração do suporte físico para o digital, visando à futura difusão e preservação e às vantagens que estas trariam ao acervo fotográfico do Curso de Arquivologia. Já os objetivos específicos consistiram em definir qual a melhor maneira de realizar a reprodução/migração de suporte das imagens fotográficas, seja em suporte papel ou filme fotográfico, quais as mídias a serem utilizadas para armazenar as cópias de segurança, qual a resolução ideal para o armazenamento das imagens e quais as normas deveriam ser adotadas para a descrição das fotografias.

Para o desenvolvimento prático da pesquisa, pretendeu-se empregar técnicas de digitalização para a documentação fotográfica, facilitando o acesso da comunidade arquivística ao acervo, agilizando a localização das imagens e diminuindo o manuseio dos originais, promovendo e aumentando, assim, as possibilidades de preservação através de métodos como a duplicação de suporte, por exemplo.

\section{Referencial teórico}

Nos tópicos a seguir, são abordados os seguintes temas: fotografia e processos fotográficos, filmes fotográficos, fotografia instantânea e fotografia digital, vantagens e desvantagens da fotografia digital, digitalização de fotografias, reprodução fotográfica, formatos para imagens fotográficas, mídias de armazenamento e bancos de dados.

\subsection{Fotografia e processos fotográficos}

Segundo o Dicionário Brasileiro de Terminologia Arquivística (2005), fotografia é toda imagem produzida pela ação da luz sobre película coberta por emulsão fotossensível, revelada e fixada por meio de reagentes químicos.

Atualmente, as imagens fotográficas, em sua maioria, formam-se sobre CCD (Charge-Coupled Device ou dispositivo de cargas encadeadas) ou componentes eletrônicos sensíveis à luz. As imagens fotográficas, depois dos documentos textuais, são os documentos encontrados com mais frequência em um arquivo, justificando, assim, o seu valor documental.

No final do século XX, com o advento das câmeras digitais, o processo de obtenção da imagem passou a ser instantâneo, mas, até chegar ao que conhecemos como fotografia hoje, muitos foram os suportes e os processos de fixação pelos quais a imagem passou. Em função disso, a fotografia foi inventada por vários pesquisadores e em diferentes países, o que terminou por provocar o surgimento de diversos processos fotográficos.

Pavão (1997) define processo fotográfico como o conjunto de processos químicos e fotoquímicos que conduzem à obtenção de uma fotografia.

Dentre os processos fotográficos mais conhecidos, estão o daguerreótipo, o calótipo ou talbótipo, o ambrótipo e o ferrótipo.

Ao descobrir, em 1826, que o betume da Judéia, quando exposto à ação da luz, tornava-se rígido/duro e insolúvel em essência de terebentina, coube a Joseph Nicéphore Niépce a façanha do descobrimento da fotografia. Este processo teve boa aceitação na época, mas, por ser muito primitivo, foram necessárias oito horas de exposição para obtenção da imagem. Como tal processo era muito lento, outros pesquisadores empenharam-se em descobrir novos meios para agilizá-lo.

Ao ter sua invenção patenteada pelo estado francês em agosto de 1839 , 
Louis Jacques Mandé Daguerre proporcionou ao mundo a, até então desconhecida, arte fotográfica.

$\mathrm{O}$ daguerreótipo nada mais era do que uma chapa de cobre coberta por uma fina camada de prata polida, sensibilizada com vapores de iodo. O processo para sua obtenção baseava-se na sensibilização de uma superfície de prata, que, quando exposta a vapores de iodo, tornava-se dourada e aumentava a sua sensibilidade à luz. Após a exposição da chapa à luz, formava-se a imagem latente, que se tornava visível sob a ação de vapores de mercúrio.

Os meios técnicos utilizados na época não permitiam a reprodução de um daguerreótipo, o que se explica pelo fato de o mesmo dar origem a imagens únicas.

No mesmo ano em que o daguerreótipo foi divulgado, o inglês William Henry Fox Talbot apresentou ao mundo sua invenção - o talbótipo, o primeiro processo negativo/positivo que permitia que, através do negativo original em papel, fossem produzidas quantas cópias positivas se desejasse.

Pelo fato de os negativos serem sobre papel, os talbótipos apresentavam uma aparência de desenho. Estes são mais raros em coleções que os demais suportes, já que, ao patentear seu invento em 1841, Talbot passou a cobrar direitos autorais dos fotógrafos que utilizassem o processo da calotipia, impulsionando o uso dos daguerreótipos, pelos quais não eram cobrados direitos. Mesmo assim, o processo negativo/positivo de Talbot foi muito importante para a fotografia, persistindo até os diais de hoje.

Em 1852, surge o ambrótipo, que é um negativo com suporte em vidro, revelado a altas temperaturas e que, ao receber por trás um veludo ou cartão -preto, aparece como um positivo (PAVÃO, 1997). Da mesma forma que o daguerreótipo, "esse conjunto era acondicionado em uma pequena caixa-estojo emoldurada. De custo inferior vieram a ser mais populares que os daguerreótipos" (FILIPPI, 2002, p. 21).

Já no ferrótipo, "a imagem era formada em uma emulsão a base de colódio e sais de prata, semelhante ao ambrótipo, porém, o suporte era uma fina chapa de metal pintada de marrom ou preto, podendo ser esmaltada ou envernizada, gerando uma imagem positiva" (FILIPPI, 2002, p. 21). Semelhante ao daguerreótipo e ao ambrótipo, o ferrótipo não permitia a produção de cópias, pois se tratava de uma imagem única.

$\mathrm{O}$ quadro abaixo apresenta os principais processos fotográficos utilizados no início da arte de fotografar, fazendo um paralelo entre o suporte, o período em que mais foram utilizados e a forma de apresentação.

\begin{tabular}{|c|c|c|c|}
\hline Processo & Suporte & $\begin{array}{c}\text { Período em que foi } \\
\text { mais utilizado }\end{array}$ & Acondicionamento \\
\hline Daguerreótipo & Metal & $1839-1855$ & Estojo \\
\hline Calótipo & Papel & $1841-1855$ & Estojo \\
\hline Ambrótipo & Vidro & $1854-1870$ & Estojo \\
\hline Ferrótipo & Metal & $1856-1890$ & $\begin{array}{c}\text { Medalhões, anéis, álbuns, } \\
\text { estojos }\end{array}$ \\
\hline
\end{tabular}

Quadro 1 - Comparativo entre os antigos processos fotográficos

Fonte: Pavão (2007); Filippi (2002). 
2.2 Filmes fotográficos, fotografia instantânea e fotografia digital

Os filmes fotográficos são compostos por um material sensível à luz, o que significa que, sob a ação da luz, sua estrutura físico-química sofre modificações. As modificações que ocorrem na estrutura das películas são decorrentes de vários fatores, como, por exemplo, do tempo de exposição à luz e da quan- tidade de luz incidente.

O filme fotográfico preto e branco é uma película que possui em sua composição uma camada protetora (gelatina), uma emulsão (gelatina com halogenetos de prata em suspensão, onde se forma a imagem), um substrato (adesivo) e uma camada anti-halo (gelatina com corante, que é eliminada durante o processamento). A figura a seguir mostra a estrutura de um filme preto e branco.

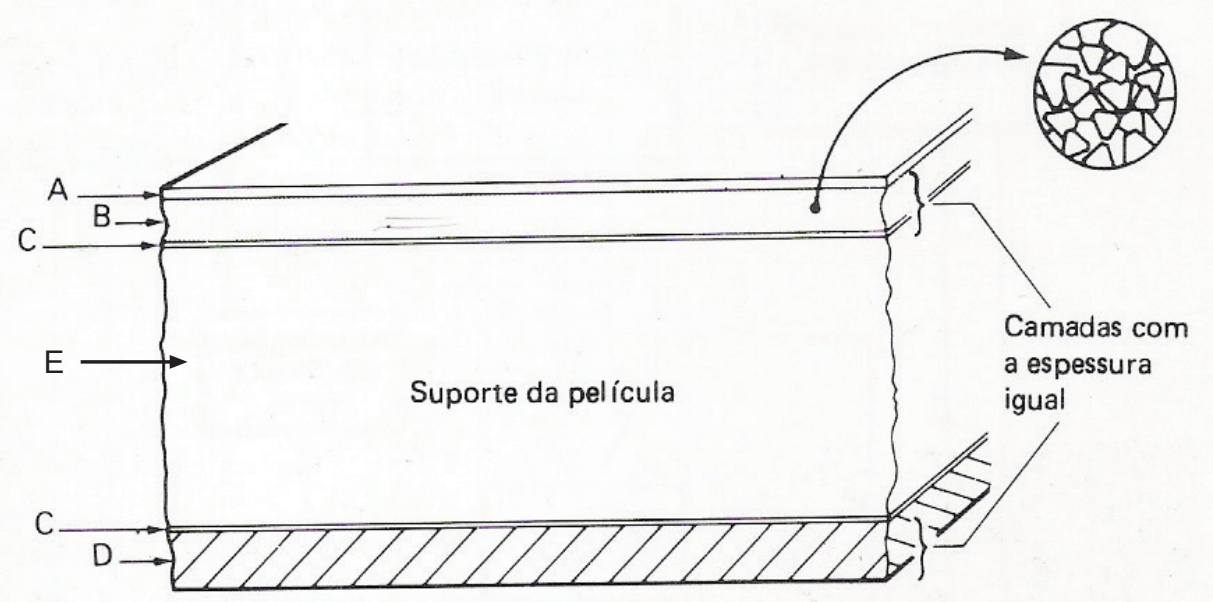

Figura 1 - Estrutura de um filme preto e branco ${ }^{4}$ Fonte: Langford (1986).

As primeiras provas de fotografia instantânea, que ficaram conhecidas pelo nome comercial de Polaroid, eram provas monocromáticas, de cor sépia e formato $8 \times 10,5 \mathrm{~cm}$. Após disparar, apenas puxava-se a ponta da prova por um compartimento onde passava entre roletes de aço, momento em que se rompia a bolsa de reagentes químicos com uma combinação de revelador e fixador, bastando apenas aguardar um minuto. A prova podia ser vista depois de despelicular, ou seja, depois de separar da prova o negativo que o cobria, o qual não era aproveitado.

Com o avanço da tecnologia e a revolução da informática, foram surgindo novos suportes para a fotografia, como é o caso da fotografia digital.
Kuhlmann (1999) enfatiza que, na fotografia, a automatização levou às câmeras digitais, as quais fotografam sem filme, utilizando-se de chips ou pequenos discos que podem armazenar inúmeras fotografias. As imagens assim captadas podem ser reproduzidas em telas de TV e monitores de vídeo, impressas em papel ou copiadas através do processo fotográfico em chips ou discos, que podem ser apagados e regravados. A câmera digital permite que as imagens possam ser enviadas a distância instantaneamente, através da internet.

As câmeras tradicionais produzem as imagens utilizando filmes com emulsões à base de cristais de halogenetos de prata sensíveis à luz. Mais tarde, as imagens são processadas em um am-

\footnotetext{
${ }^{4}$ A - Camada Protetora (Gelatina), B - Emulsão (Gelatina com halogeneto de prata em suspensão), C - Substrato (Adesivo), D - Camada anti-halo (Gelatina com corante escuro), E - Base (Suporte sobre a qual é fixada a emulsão).
} 
biente escuro em banhos químicos a fim de torná-las permanentes. As câmeras digitais focalizam as imagens em um chip semicondutor, sensível à luz, denominado Charge-Coupled Device (CCD ou dispositivo de cargas encadeadas). $\mathrm{O}$ CCD atua como substituto do filme para transformar a imagem capturada em pixels (equivalentes aos grãos dos filmes baseados em prata; quanto mais pixels houver em uma área, mais detalhes podem ser registrados).

As câmeras digitais utilizam cartões de memória para o armazenamento das fotografias. Estes armazenam as fotos em arquivos RAW, de modo que, após a escolha do formato desejado (JPEG, TIFF, GIF etc.), basta transferir o conteúdo dos cartões para o disco rígido do computador para que se possa ver a foto, editá-la ou imprimi-la.

No início, quando as máquinas digitais foram lançadas, a única maneira de conectá-las ao computador era através da porta serial, o que era extremamente lento. Hoje, as câmeras são conectadas à porta USB do computador ou até mesmo diretamente pelo cartão de memória, sendo possível transferir as imagens de modo bem mais rápido.

Existem vários formatos de cartões de memória no mercado, pois os fabricantes de máquinas digitais, ao invés de adotarem um único padrão, lançaram o seu próprio padrão. Entre esses formatos, destacam-se o Compact Flash (CF), Memory Stick (MS), Multi Media Card (MMC), Secure Digital (SD), Secure Digital High Capacity (SDHC), Smart Media (SM) e eXtreme Digital (xD), que é o formato desenvolvido para substituir o Smart Media, sendo de tamanho menor e possuindo maior capacidade de armazenamento.

Schäfer e Flores (2011) apontam que, atualmente, a capacidade de armazenamento dos cartões é definida de acordo com cada modelo, podendo variar de 1 GB a 128 GB, e, como não utilizam a porta USB para acesso aos dados ou para leitura, são necessárias entradas de leitura/gravação compatíveis com os modelos de cada cartão de memória.

\subsection{Vantagens e desvantagens da foto- grafia digital}

Muitas são as vantagens da fotografia digital. As câmeras digitais são leves e fáceis de carregar. Não é necessário comprar filme nem pagar pela revelação das imagens, como ocorre com as fotografias tradicionais. É preciso comprar, no entanto, cartão de memória e pode haver, ainda, custos com a impressão das fotos, caso seja necessário montar um álbum com as fotografias impressas.

Outro fator importante é não precisar esperar que o filme seja revelado nem que as impressões sejam feitas e escaneadas, pois, na fotografia digital, os detalhes podem ser examinados, com o auxílio do dispositivo zoom, logo após as fotos terem sido tiradas. Estas podem ser exibidas no monitor de uma TV, bastando, para isso, conectar o cabo que acompanha a câmera. A transferência das fotos da câmera para o computador leva apenas alguns segundos.

Além disso, as câmeras digitais permitem ainda que sejam deletadas as fotos que apresentarem problemas, evitando, dessa forma, o desperdício de memória. As fotografias que não ficaram boas podem ser tiradas outra vez. Isso facilita e agiliza a reprodução de fotos e documentos, além de permitir o desenvolvimento de banco de imagens.

Outra vantagem advém da rápida evolução dos programas para o tratamento das imagens e da evolução das capacidades de memórias de armazenamento para fotografias, que facilitam o acesso e a transmissão dessas imagens via web e a inclusão de fotos em textos e artigos acadêmicos, por exemplo.

Existem, também, algumas desvantagens em utilizar uma câmera digital. A principal é o custo. As câmeras digitais mais sofisticadas são ainda muito caras e seu uso implica o gasto com aquisição de pilhas/baterias de re- 
serva, já que as pilhas descarregam rapidamente. Nesse contexto, conforme afirma Rose (1999), uma boa alternativa é o uso de baterias de lítio, as quais proporcionam maior duração da carga. Dois conjuntos de baterias recarregáveis e um carregador são, assim, um bom investimento.

Pelo fato de a fotografia digital ter custos reduzidos, aumentou o número de imagens sem identificação, pois não há preocupação com a seleção das imagens, tornando-se mais difícil a localização de certas fotografias e havendo um aumento de custos com mídias de armazenamento.

2.4 Digitalização de fotografias e reprodução fotográfica

Monte (2003) entende por digitalização a tecnologia que transfere digitalmente uma fotografia eletrônica de um documento em papel para um sistema computacional. Após tal conversão, as imagens eletrônicas são indexadas, comprimidas e armazenadas em dispositivos de armazenamento óptico, magnético e/ou eletrônico.

A digitalização das fotografias pode ser executada através de scanners, os quais capturam as imagens já impressas e as transformam em imagens digitais, de forma semelhante ao que ocorre com as imagens capturadas em uma câmera digital. Existem vários tipos de scanners, desde os mais simples, que capturam somente imagens impressas, aos mais sofisticados, que podem digitalizar até mesmo negativos.

A melhor definição para scanner seria digitalizador de imagens, pois é através dele que se converte uma imagem para o formato digital antes da transferência para um computador. $\mathrm{O}$ seu funcionamento é simples. Como explica Alecrim ${ }^{5}$ (2004), um sensor capta a luz refletida pela figura formando uma imagem digitalizada. Os modelos de scanners e sua forma de trabalho são os 5 Fonte: ALECRIM, Emerson. Scanners. Disponível em: $<$ http://www. infowester.com/scanners.php $>$. Acesso em: 08 mar 2012. mais diferentes possíveis.

Hornstein (1996) afirma que os originais a serem digitalizados se enquadram em duas categorias: transmissivos ou refletivos. Transmissivo é aquele em que a imagem é vista principalmente pela luz que passa através dela. Estão incluídos nesta categoria as transparências (como slides de $35 \mathrm{~mm}$ ) e todos os negativos. Os scanners que utilizam esse recurso são scanners para filmes fotográficos, para microfilmes e de mesa com torre para slide. Já os originais refletivos são vistos pela luz refletida na sua superfície. As fotografias são originais refletivos. Utilizam esse recurso, principalmente, os scanners de mesa, com alimentador automático, multifuncional e, inicialmente, também os de mão, de bolso e de tambor.

Os scanners podem ainda ser divididos quanto ao uso que deles é feito. Os de uso profissional são aqueles que apresentam um resultado de melhor qualidade, porém, são um pouco mais caros. São eles: scanner de Tambor, com alimentador automático, para filmes fotográficos e para microfilmes. Os scanners de uso amador são aqueles que podem proporcionar imagens de boa qualidade a um preço mais acessível. São eles: scanner de mesa, de bolso e multifuncional.

Para a digitalização de fotografias, pode, ainda, ser utilizada uma mesa de reprodução, a qual permite o acoplamento de uma câmera fotográfica que favorece e acelera a reprodução de fotografias. Quanto ao tempo necessário para digitalizar uma imagem, na câmera digital, essa prática é de frações de segundos e, no scanner, é de quase um minuto para digitalizar uma imagem.

A mesa de reprodução permite, ainda, um melhor manejo das fotografias a serem digitalizadas, visto que, através da conexão da câmera a um monitor de $\mathrm{TV}$, é possível ter uma visão completa e ampliada da imagem a ser digitalizada, facilitando, dessa forma, a correção de qualquer erro que possa surgir durante $o$ enquadramento, o ajuste de foco etc. 


\subsection{Formatos para imagens fotográficas}

É imprescindível para o arquivista conhecer os principais formatos e tamanhos de arquivo, pois este deverá ter noção de qual formato utilizar para determinada situação, levando em conta a perda da qualidade que a escolha de um formato inadequado pode acarretar às imagens.

Depois de finalizado o processo de captura das fotografias digitais, é preciso salvá-las em um formato apropriado às suas finalidades. Se a fotografia for usada na internet, será preciso convertê-la para um arquivo JPEG (Joint Photographic Experts Group) ou GIF (Graphic Image Formato). Esses são os dois principais formatos interpretados pelos browsers da Web. Se a imagem for utilizada para editoração eletrônica ou como parte de um documento impresso, poderá ser necessário convertê-la para um formato de arquivo TIFF ou PSF (PostScript) a fim de que possa ser utilizada em impressoras PostScript.

O compactador JPEG tem muitas vantagens na fotografia digital, já que foi desenvolvido para trabalhar com imagens digitais, podendo trabalhar com as diversas cores que existem na fotografia. Já o GIF restringe trabalhar a imagem digital com no máximo 256 cores.

Em se tratando de formato para imagens digitais, cabe destacar ainda o formato RAW, que, de acordo com Schäfer (2013, p. 63), é o formato "capaz de guardar todos os dados de uma foto tal como foi gerada no equipamento, sem aplicação de efeitos ou ajustes, oferecendo alta qualidade na imagem e maior profundidade de cores". O autor comenta, ainda, que, por apresentar dados puros (remetendo ao nome "cru" ou "não processados"), o responsável pelo arquivo pode aplicar efeitos e ajustes.

O CONARQ (2010, p. 10) também destaca esse formato, explicando que "o RAW é um formato proprietário (cada fabricante apresenta seu próprio formato que o faz dependente de hard- ware e software específicos) [...] Além disso, não há a necessidade obrigatória de conservar o arquivo neste formato". Nesse sentido, é comum que os arquivos inicialmente em RAW sejam convertidos para formatos como TIFF, JPEG ou PNG. Como o formato RAW é o primeiro registro do arquivo digital, acaba sendo considerado como o "negativo digital" das fotografias.

\subsection{Mídias de armazenamento e bancos} de dados

Monte (2003) aponta que, na Ciência da Informação, suporte da informação significa o produto utilizado para o armazenamento das informações, podendo conter dados, documentos, imagens, filmes, entre outros. Com a popularização da informática, esses produtos passaram também a ser chamados de mídias ou dispositivos de armazenamento.

Entre os suportes encontrados na atualidade, destacam-se os dispositivos de armazenamento magnético e os de armazenamento óptico. Os dispositivos de armazenamento magnético mais comuns são as fitas magnéticas, os disquetes e os discos rígidos. Atualmente, a mídia pen drive também surge como uma opção de armazenamento de informações. $\mathrm{O}$ armazenamento em fita é utilizado para dados que não são utilizados com muita frequência, pois, como a fita é uma longa tira de material magnético, a unidade de fitas grava os dados sequencialmente, um após o outro, tornando o acesso aos dados mais lento. A utilização do disquete foi limitada ao início da fotografia digital para o armazenamento de imagens, pois um disquete de 1,44 MB não era capaz de armazenar nem mesmo uma fotografia em alta resolução, já que as primeiras câmaras apresentavam baixa resolução.

Atualmente, o próprio disco rígido do computador e um HD portátil/externo são alguns dos principais dispositivos de armazenamento. Como eles são 
capazes de armazenar muitos dados, às vezes, são chamados de dispositivos de armazenamento de massa ou memória de massa e, como apontado por Schäfer e Flores (2011), armazenam mais de 500 GB de informação, possibilitando criar diretórios que facilitam a organização dos documentos.

O pen drive é um dispositivo de memória que funciona como unidade de armazenamento removível. Sua vantagem é ser compacto e ter uma grande capacidade de armazenamento (hoje, já encontramos pen drives com até 500 GB de capacidade de armazenamento). Além disso, a velocidade na leitura e gravação de dados é superior a de discos óticos CD/DVD, por exemplo.

Já os dispositivos de armazenamento óptico utilizam o raio laser para a leitura ou gravação de dados em CD (Compact Disc) ou em DVD (Digital Versatile Disc). Durante muito tempo, os CD's foram mídias utilizadas exclusivamente para leitura. Mas, com a popularização dos gravadores, passaram a ser utilizados, também, para o armazenamento de músicas, jogos, dados, programas e filmes. Desse modo, atualmente existem os CD-R (CD gravável) e os CD-RW (CD regravável). Os CD's graváveis (CD-R) trazem a desvantagem de não permitirem regravação. Para isso, surgiram os CD's regraváveis (CR-RW), que podem ter seu conteúdo alterado livremente, praticamente com a mesma facilidade que se tinha com as mídias Zip e disquetes.

O DVD (Digital Versatile Disc) é um disco que contém informações digitais, tendo maior capacidade de armazenamento que o CD- ROM, devido a uma tecnologia óptica superior, além de padrões melhorados de compressão de dados. A família $\mathrm{DVD}^{6}$ possui os mesmos membros da família $\mathrm{CD}$, existindo o DVD-ROM (gerado em linhas industriais), o DVD-R ("recordable", gra-

${ }^{6}$ Fonte: BARREIROS, Adriana de Almeida. A durabilidade dos suportes eletrônicos e a preservação da informação. Disponível em: http://www. arquivar.com.br/espaco_profissional/sala_leitura/teses-dissertacoes-emonografias/A durabilidade dos Suportes_Eletronicos_e a Preservacao_da_Informacao.pdf/view. Acesso em: 08 mar 2012. vável em casa) e o DVD-RAM (DVD regravável).

A capacidade máxima de um DVD anunciada no mercado é de 4,7 GB para uma face e uma camada, 9 GB para uma face e dupla camada e 17 GB para duas faces e duas camadas. Os formatos mais recentes de DVD's de alta definição, como apontam Schäfer e Flores (2011), são característicos por sua alta capacidade de armazenamento, como o Disco Blu-ray (Blu-ray Disc), que, ao invés do raio laser vermelho, utiliza raio laser azul, permitindo um facho de luz mais estreito e preciso. Esta tecnologia possui maior velocidade de transferência e possibilita a gravação de mais informação que tecnologias anteriores (CD e DVD), armazenando o equivalente a 50 Gigabytes.

O banco de dados é um instrumento que ganha maior espaço na atualidade, pois, com o aumento dos documentos em formato digital, são necessários instrumentos que tornem mais rápido o armazenamento e a recuperação das informações.

A utilização de banco de dados na gestão eletrônica de fotografias, além de garantir maior organização e padronização das imagens, possibilita a preservação das imagens originais, evitando, dessa forma, o seu manuseio e/ou extravio.

\section{Método}

Este artigo, que trata do relato das atividades de migração de suporte de fotografias desenvolvidas durante a graduação em Arquivologia, no período de 2007 e 2008, é de natureza aplicada, pois focou a solução de um problema específico envolvendo dados de interesse local. O foco deste estudo foi o Arquivo Fotográfico do Curso de Arquivologia da Universidade Federal de Santa Maria, procurando-se verificar a melhor forma para realizar a migração de suporte das fotografias em papel através de sua reprodução com a utilização de Câmeras Fotográficas Digitais. 
Levando em consideração a forma de abordagem do problema, a pesquisa definiu-se como qualitativa, pois os dados foram analisados de acordo com o ambiente natural da pesquisa, não necessitando de análise estatística, mas descritiva. Do ponto de vista dos objetivos, a pesquisa enquadrou-se como exploratória, uma vez que foi necessário reunir material bibliográfico sobre o tema. Por se tratar de um tema atual e em constante evolução, boa parte do referencial teórico foi levantada a partir de livros, artigos e textos disponíveis na internet. Procurou-se enfocar, principalmente, informações sobre a história da fotografia, os processos fotográficos, os equipamentos fotográficos, a fotografia digital, o processo de digitalização, a reprodução fotográfica e as mídias de armazenamento para fotografias.

Considerando os procedimentos técnicos, a pesquisa assumiu características de um estudo de caso, tendo sido realizadas entrevistas informais sobre o acervo com o professor responsável pela junção das imagens que deram origem ao Arquivo Fotográfico. Esse professor ministrou um rápido curso de treinamento para utilização das mesas de reprodução, do scanner para filmes, do controle de iluminação e das resoluções para armazenamento das fotografias, tendo sido demonstrada a utilização da TV como monitor nessa ocasião.

Nesse sentido, visando melhorar o acondicionamento e a preservação das fotografias em suporte papel, através da diminuição do manuseio dos originais e aumentar o acesso ao acervo, pretendeu-se, no decorrer do trabalho, digitalizar as imagens que ainda se encontravam em suporte filme/papel fotográfico e implantar um sistema de banco de dados que se adaptasse melhor às necessidades do referido setor.

Tratando-se da migração de suporte por reprodução fotográfica, alguns cuidados especiais foram tomados, tais como manter a sala onde era realizada a reprodução das imagens sem iluminação oriunda do teto, controlar a iluminação natural por meio de cortinas e manter certa distância entre as duas mesas de reprodução para que a luz de uma não interferisse na outra.

Realizou-se, também, a retirada das fotografias em papel das pastas suspensas e dos envelopes armazenados no arquivo de aço, bem como o seu recondicionamento após a digitalização. Utilizou-se, ainda, de técnicas para a confecção de envelopes a partir de papel neutro e cola neutra metilcelulose para as fotografias que ainda não estavam acondicionadas no arquivo de aço.

Paes $(2005$, p. 22) chama atenção para o fato de que documentos em suporte especial, como é o caso das fotografias, devem receber "tratamento especial não apenas no que se refere ao seu armazenamento, como também ao registro, acondicionamento, controle, conservação, etc." Nesse sentido, técnicas adequadas devem ser empregadas a fim de preservar os materiais fotográficos.

De acordo com Brito (2010), a higienização de fotografias pode ocorrer de forma mecânica, removendo-se as sujeiras superficiais das imagens por meio da utilização de capelas de exaustão e de trinchas, da aplicação de pó de borracha no verso da imagem, de pincel soprador, de ar comprimido e de algodão; ou de forma química, aplicando-se solventes nas fotografias para a remoção de resíduos de cola, fitas adesivas, grampos e excrementos de insetos. Quando essencialmente necessário, utiliza-se, sobre a parte emulsionada da fotografia, algodão com álcool etílico e água. No verso da imagem, podem ser aplicados materiais como: cola de metil, água destilada e, em alguns casos muito específicos, após testes em uma pequena parte da imagem, álcool ou mesmo acetona.

Ressalta-se que, durante a preparação das fotografias para digitalização, não foram realizadas atividades de higienização, pois o acervo fotográfico apresentava boas condições de conservação. 
As fotografias em papel, depois de digitalizadas, juntamente com as fotografias digitais armazenadas no computador, foram descritas no Banco de Dados Access segundo o Código de Catalogação Anglo-Americano - $2^{\mathrm{a}}$ edição (CCAA2). A escolha por esse código para a descrição das imagens deu-se pelo fato de um significativo número de fotos já terem sido descritas segundo tal parâmetro. Uma mudança ocasionaria um aumento dos prazos, ultrapassando os que haviam sido estabelecidos para a conclusão do projeto de migração das fotografias.

\section{Apresentação e discussão dos resul- tados}

No Arquivo Fotográfico do Curso de Arquivologia da UFSM, as primeiras fotografias foram reveladas em preto e branco e as coloridas eram processadas em laboratórios fotográficos comerciais e arquivadas em envelopes de papel neutro, sendo armazenadas em pastas suspensas em um arquivo de aço, segundo terminologia adotada pelos técnicos da Biblioteca Nacional com três níveis de proteção compostos pelos envelopes (1) dentro de pastas (2) armazenadas em arquivo de aço (3).

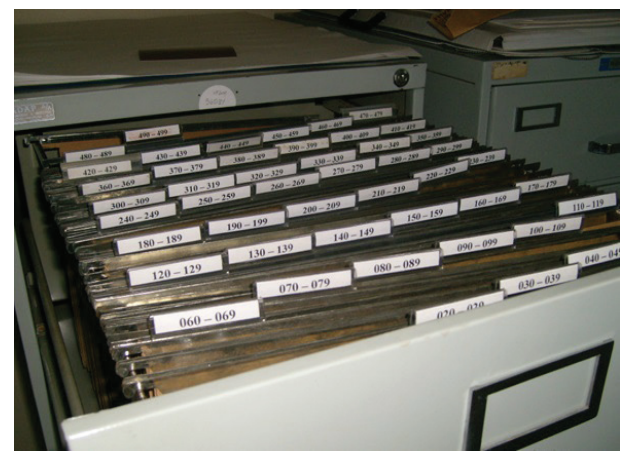

Figura 2 - Armazenamento de fotografias em papel fotográfico

Fonte: autoria de Eliseu dos Santos Lima

Os envelopes em papel neutro são indicados para o acondicionamento de fotografias, pois as protegem da luz e do pó e não as isolam do ambiente, permitindo a ventilação das mesmas, o que não ocorre quando elas são colocadas em álbuns com proteção ou bolsas de plástico, correndo o risco de grudar (principalmente as imagens em papel brilhante) ou mofar mais facilmente. Os envelopes neutros também protegem as fotografias das variações de temperatura e umidade, que, de acordo com o Arquivo Nacional (2005), devem estar entre $\mathrm{T} 12^{\circ} \mathrm{C} \pm 1{ }^{\circ} \mathrm{C}$ e UR $35 \% \pm 5 \%$ para fotografias em preto e branco e $\mathrm{T} 5^{\circ} \mathrm{C} \pm$ $1{ }^{\circ} \mathrm{C}$ e UR $35 \% \pm 5 \%$ para fotografias coloridas.

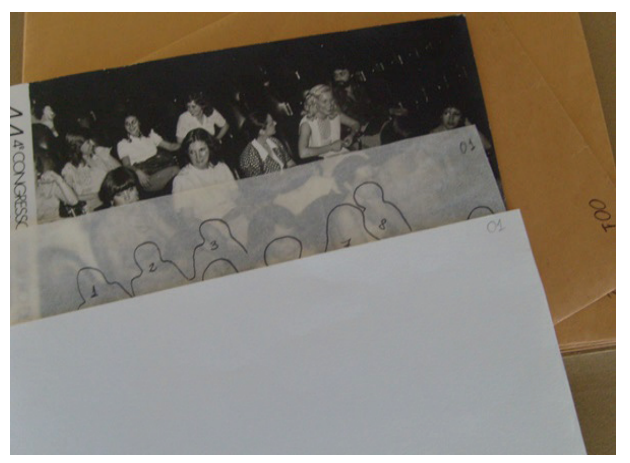

Figura 3 - Nível de proteção das fotografias Fonte: autoria de Eliseu dos Santos Lima

O Arquivo Fotográfico do Curso de Arquivologia está localizado na sala 2154 do Prédio 74 no campus da UFSM e sua estrutura dispõe de um arquivo de aço, em que estão armazenadas as cópias em papel das fotografias, e possui, também, uma lupa com sub-iluminador, duas mesas de reprodução, um computador com um scanner de mesa, um scanner para filmes fotográficos de 35 $\mathrm{mm}$ e uma TV 21 polegadas, utilizada como monitor para melhor visualizar as imagens a serem digitalizadas.

Atualmente, as fotografias em suporte papel contam com aproximadamente novecentas (900) imagens (preto e branco e coloridas), em tamanhos que variam de $9 \times 12$ a $20 \times 25$. Tanto as fotografias em preto e branco como as coloridas seguem o mesmo padrão de arquivamento, sendo armazenadas em envelopes neutros, que são acondicionados em pastas suspensas no arquivo de aço.

O Arquivo Fotográfico do Curso de Arquivologia possui, ainda, aproxi- 
madamente duas mil e trezentas (2.300) fotos digitais, que foram tiradas com duas câmeras fotográficas do Laboratório fotográfico do Curso, ambas de 5 megapixels. A mais simples é utilizada pelos alunos para realizarem trabalhos acadêmicos, diagnósticos em projetos de arquivo e eventuais registros de solenidades. A outra câmera é utilizada somente no Laboratório fotográfico para o desenvolvimento de projetos.

O professor responsável pelas disciplinas de Fotografia e Registros Iconográficos, do Mestrado Profissional em Patrimônio Cultural, e Reprografia, disciplina do Curso de Arquivologia, também utiliza câmeras digitais (particulares) com a resolução média de 3 a 5 megapixels, principalmente para eventos realizados fora da UFSM.

O Arquivo Fotográfico também recebe doações de fotografias dos professores e alunos, incluindo imagens importantes de eventos e solenidades realizadas (congressos, seminários etc.) tanto nas dependências da UFSM como em outros locais, as quais ajudam na preservação da memória institucional.

$\mathrm{O}$ armazenamento atual dessas fotografias é feito no disco rígido do computador do Arquivo do Curso de Arquivologia. Boa parte dessas imagens está armazenada no Banco de Dados Access e descrita de acordo com o Código de Catalogação Anglo-Americano - $2^{\mathrm{a}}$ edição (CCAA2) e conta com um backup em HD externo.

O método escolhido para a digitalização das fotografias do Arquivo Fotográfico do Curso de Arquivologia foi a reprodução fotográfica (foto da foto), em virtude de este processo apresentar vantagens em relação à digitalização realizada com um scanner, como a rápida passagem da imagem para o cartão de memória com apenas um apertar de botão, o que levaria um tempo maior na digitalização por meio de scanner. Além disso, as imagens digitalizadas por reprodução fotográfica ficam todas do mesmo tamanho.
Quanto à migração de suporte por reprodução fotográfica, alguns cuidados especiais foram tomados, como: controlar a proximidade entre as duas mesas de reprodução para que a luz de uma não incidisse sobre a outra; evitar o uso de roupas claras durante a digitalização; controlar a iluminação da sala, mantendo as lâmpadas fluorescentes apagadas; e controlar a iluminação natural através de cortinas para que a luz não interferisse quando as fotografias fossem reproduzidas por meio de câmeras digitais.

As câmeras digitais foram acopladas a duas mesas de reprodução: uma com controle de iluminação através de refletores móveis e do uso de lâmpadas fluorescentes brancas, também conhecidas como lâmpadas "frias" de 25 watts, já que as câmeras digitais fazem os devidos ajustes para utilizar este tipo de iluminação, dispensando, dessa forma, o uso do flash da câmera; outra com controle de iluminação por meio de braços articulados, permitindo a mobilidade das lâmpadas, e de regulagem de altura, permitindo adequar o exato enquadramento da foto a ser reproduzida e trabalhar com alimentador de energia para a câmera, tendo em vista a curta duração das baterias recarregáveis.

Inicialmente, as fotografias em papel foram digitalizadas com os equipamentos disponíveis na época - duas câmeras fotográficas - uma Sony W1, com 5.0 megapixels de resolução, objetiva Carl Zeiss, zoom ótico de 4x, controle manual e cartão de memória com 256 MB de capacidade (nesta câmera, foi utilizada a resolução máxima, que é de 5 megapixels, em função de que as imagens reproduzidas com essa resolução seriam utilizadas como cópias de segurança (backup) com no mínimo duas cópias em DVD) e uma Sony P93 Cyber-Shot, com 5.1 megapixels (utilizada em função da necessidade de imagens com baixa resolução para serem inseridas no Banco de Dados).

As fotografias foram digitalizadas até que os cartões de memória atin- 
gissem a sua capacidade máxima. Após, as imagens foram transferidas para o HD do computador e salvas no formato JPEG, sendo, posteriormente, inseridas no banco de dados e tendo suas cópias de segurança feitas.

Vale frisar que as imagens não receberam tratamento para a correção de possíveis defeitos que pudessem surgir durante a digitalização, como brilho, contraste, recorte etc. Após a reprodução das imagens, as fotografias em papel que ainda não estavam armazenadas no arquivo de aço foram acondicionadas em envelopes e pastas suspensas. Estas imagens seguiram a numeração sequencial das imagens que já haviam sido catalogadas, para também serem descritas no banco de dados.

Após o acondicionamento das fotografias no arquivo, as imagens já digitalizadas passaram por uma conferência para que as fotografias digitais tivessem a mesma numeração das fotografias tradicionais em papel. Este processo foi realizado para facilitar a inserção das imagens no banco de dados e permitir a busca das fotografias originais no arquivo.

O Banco de Dados utilizado para descrever as fotografias foi o Microsoft Access, respeitando a sequência das fotografias já descritas, com os seguintes campos, segundo o Código de Catalogação Anglo-Americano - $2^{\mathrm{a}}$ edição (CCAA2): Número da foto, Imagem, Local, Evento, Data, Largura, Altura, Procedência, Suporte, Cromia, Nitidez, Conservação, Identificação e Histórico. Acrescentou-se, ainda, o campo de descrição Fotografia (em Objeto Ole, para que fosse possível visualizar a fotografia sem ser necessário acessar o link com a fotografia original).

Apesar de o Access ser um banco de dados conhecido, amigável, este apresenta sua capacidade de armazenamento limitada (6 GB). As fotografias, ao serem inseridas em seu tamanho original dentro do banco de dados, expandem-se e ocupam mais espaço, impossibilitando, dessa forma, o armaze- namento de muitas delas.

Para evitar que ocorresse a expansão das fotografias ao serem inseridas no campo Objeto Ole, optou-se por usar uma imagem em miniatura da fotografia original (Thumbnail), de modo que todas as fotografias, através de um conversor de imagens, foram convertidas de uma resolução média de $100 \mathrm{~KB}$ para uma resolução menor de 10 a $15 \mathrm{~KB}$.

As mídias utilizadas para o armazenamento das fotografias, além do HD do computador em que as imagens estão armazenadas, foram DVD's, dos quais, periodicamente, eram feitas cópias de segurança. Isso proporciona outro meio de armazenamento para situações de emergência, além da segurança já possibilitada pela duplicação de mídia. Atualmente, são feitas cópias de segurança em um HD externo de 500 GB.

As imagens que se encontravam em suporte filme (negativos e diapositivos) foram digitalizadas por um scanner $35 \mathrm{~mm}$, o qual levou um tempo razoavelmente longo (aproximadamente um minuto) para digitalizar cada imagem e não permitiu que as imagens fossem salvas com uma resolução menor que $60 \mathrm{MB}$, o que não é amigável para reduzir a resolução.

Tendo em vista o estudo e a prática sobre a migração das fotografias em papel para o meio digital e os fatores que envolvem tal processo, percebe-se o quanto este é fundamental para que as fotografias sejam preservadas e estejam disponíveis à pesquisa, democratizando o acesso às informações contidas nestas imagens, que trazem registradas a história do Curso de Arquivologia em mais de três décadas de existência.

\section{Considerações finais}

A pesquisa sobre migração de suporte para a preservação de acervos fotográficos permitiu que fossem levantadas algumas considerações a partir dos resultados obtidos pelo estudo de caso feito no arquivo fotográfico do Curso de 
Arquivologia da UFSM.

Considera-se que a reprodução/ migração de suporte das fotografias por reprodução fotográfica foi o método mais adequado às necessidades do Arquivo Fotográfico do Curso, uma vez que o acervo deste possui um número significativo de fotografias em papel. O processo por reprodução fotográfica torna mais rápido o processo de digitalização das imagens, ao contrário da reprodução com um scanner de mesa, por exemplo, que exige um tempo considerável para uma fotografia ser digitalizada. Com a utilização de uma câmera digital acoplada a uma mesa de reprodução, esta prática resume-se a um apertar de botão para que a imagem já esteja armazenada digitalmente. Além disso, esta forma de migração não apresenta disparidade no tamanho das imagens digitalizadas, uma vez que as fotografias são todas salvas com tamanho padrão.

Já para a digitalização de filmes fotográficos, verificou-se que o método mais adequado é a utilização de um scanner para slides e filmes $35 \mathrm{~mm}$. Este aparelho digitaliza esses suportes com uma resolução bastante alta, o que causa certa dificuldade para a redução da mesma, o que se deve ao fato de que quanto menor for o suporte da imagem original maior deverá ser a resolução utilizada.

As cópias de segurança (backup) foram realizadas em DVD's, por ser esta a mídia de armazenamento disponível no momento de finalização do trabalho de migração das fotografias.

A forma mais indicada para o armazenamento de segurança das fotografias do Curso de Arquivologia é o processo de espelhamento, que consiste na utilização de dois HD's no mesmo computador, com uma cópia sendo feita no segundo HD todos os dias ou quando o computador for desligado. Dessa forma, caso ocorresse algum erro em um dos HD's, as informações estariam salvas no segundo HD, evitando, assim, a perda das fotografias.

Sugeriu-se, também, a utilização da mídia pen drive, por apresentar diversos aspectos vantajosos, como: capacidade de armazenamento em constante evolução (atualmente, existem pen drives de até 500 GB de capacidade de armazenamento), independência de softwares para que as fotografias sejam gravadas, velocidade na leitura e gravação de dados superior a outras mídias etc.

Quanto à resolução das imagens reproduzidas fotograficamente, recomendou-se que, para o armazenamento e para as cópias de segurança, a resolução fosse a maior possível. No caso das fotografias do Curso, foi utilizada a resolução máxima das câmeras disponíveis na época (5 megapixels). Isso permite a percepção de maiores detalhes e nitidez das imagens.

Atualmente, o ideal é a utilização de imagens em RAW (formato cru), que são consideradas as formas de registro mais próximas dos negativos fotográficos em função de sua fidelidade de reprodução dos originais.

Para a utilização das fotografias em Banco de Dados, é aconselhável o uso de uma resolução leve, tipo VGA. Em relação a isso, toma-se como exemplo a utilização do Banco de Dados $A c$ cess da Microsoft, que, ao abrigar fotografias em média ou alta resolução, tem grande parte de seu espaço ocupado, não permitindo o armazenamento de grandes quantidades de fotografias, pois as fotos em JPEG estão compactadas e ao serem inseridas voltam ao tamanho original.

Uma das soluções para esta questão seria a conversão das fotografias a serem utilizadas no banco de dados para uma resolução menor, permitindo, assim, que um número maior de fotografias seja inserido.

Para a descrição das fotografias, seguimos utilizando o Código de Catalogação Anglo-Americano - $2^{\mathrm{a}}$ edição (CCAA2), que já vinha sendo utilizado desde a descrição das primeiras imagens que integraram o arquivo, o que indica que este já contava com um grande número de fotografias descritas. 
É de se considerar que outras normas para a descrição das fotografias possam ser utilizadas, como a SEPIADES (Sepia Data Element Set), que é um modelo exclusivo e padronizado para a descrição de fotografias independente do suporte em que estas se encontrem (slide, filme etc.). Dessa forma, existindo uma norma específica para a descrição de fotografias, não mais seria necessária a adoção de normas mais abrangentes, que, por vezes, não satisfazem uma descrição eficiente dos suportes fotográficos.

Observou-se, com o desenvolvimento deste estudo, que a organização de um acervo fotográfico, assim como os demais tipos documentais, é um trabalho moroso que requer dedicação e persistência, pois os resultados não são imediatos.

Durante a realização do trabalho, muitas fotografias foram catalogadas e reproduzidas, ficando, assim, disponíveis para aqueles que delas desejassem fazer uso. No entanto, algumas fotografias continuaram sem tratamento e precisam ser catalogadas e indexadas ao arquivo para também serem digitalizadas, pois, devido à exiguidade do tempo, não foi possível concluir o trabalho.

Sugere-se a continuidade da organização do acervo, o que pode ser feito semestralmente por um bolsista (que, preferencialmente, já tenha cursado a disciplina de Reprografia) que dê suporte às atividades de organização do acervo fotográfico, visto que periodicamente o arquivo recebe novas fotografias, necessitando, assim, de um monitoramento constante.

Nestes documentos tão importantes para a comunidade arquivística, estão registrados a história e o percurso do Curso de Arquivologia da Universidade Federal de Santa Maria e (por que não dizer) os primeiros registros visuais do desenvolvimento do ensino de Arquivologia no Brasil.

Com este projeto, propicia-se a preservação dos documentos fotográficos, permitindo criar um senso de identidade e significação entre indivíduos e o meio em que atuam e vivem. Consequentemente, através desses registros fotográficos, retrata-se uma pequena parte da trajetória da UFSM que contribui significativamente para que se construa e mantenha a sua memória institucional.

\section{Referências}

1. ALECRIM, E. Scanners. Disponível em: <http://www.infowester.com/scanners.php>. Acesso em: 08 mar. 2012.

2. ARQUIVO NACIONAL (Brasil). Dicionário Brasileiro de Terminologia Arquivística. Rio de Janeiro: Arquivo Nacional, 2005. 232 p; $30 \mathrm{~cm}-$ Publicações técnicas; $n^{\circ} .51$

3. ARQUIVO NACIONAL (Brasil). Recomendações para a produção e o armazenamento de documentos de arquivo. - Rio de Janeiro: Conselho Nacional de Arquivos, 2005. Disponível em: < http://www.conarq.arquivonacional.gov.br/Media/publicacoes/ recomendaes_para_a_produo.pdf $>$. Acesso em: 18 set 2013 .

4. BARREIROS, A. de A. A durabilidade dos suportes eletrônicos e a preservação da informação. Disponível em: <www.arquivar.com.br/ espaco_profissional/sala_leitura/teses-dissertacoes-e-monografias/A_durabilidade_dos_Suportes_Eletrônicos_e_a_Preservacao_da_Informacao. pdf/view>. Acesso em: 08 mar. 2012.

5. BRITO, L. S. Histórias e memórias institucionais a partir do acervo fotográfico do Centro Universitário Franciscano (1955-1980). 2010. Dissertação (Curso de Mestrado Profissionalizante do Programa de Pós-graduação em Patrimônio Cultural) - Universidade Federal de Santa Maria, Santa Maria, 2010.

6. CONSELHO NACIONAL DE ARQUIVOS (Brasil). Resolução $\mathrm{N}^{\circ} 31$, de 28 de abril de 2010. Dispõe sobre a adoção das Recomendações para Digitalização de Documentos Arquivísticos 
Permanentes. 2010. Disponível em: < http://www.conarq.arquivonacional. gov.br/media/publicacoes/recomenda/ recomendaes_para_digitalizao.pdf $>$. Acesso em: $2 \overline{7}$ set $2 \overline{0} 13$.

7. FILIPPI, P. de. Como tratar coleções de fotografias/Patrícia de Filippi, Solange Ferraz de Lima, Vânia Carneiro de Carvalho. - São Paulo: Arquivo do Estado: Imprensa Oficial do Estado, 2002 .

8. HORNSTEIN, J. Scanner: digitalização de imagens/Jonathan Hornstein; Tradução de Follw-up Traduções. - Rio de Janeiro: Campus, 1996.

9. KUHLMANN, P. E. Um panorama da produção fotográfica: Processos foto-químicos e eletrônicos de obtenção de imagem fotográfica. 1999. $118 \mathrm{f}$. Monografia (Dissertação em Engenharia da Produção) - Universidade Federal de Santa Maria, Santa Maria, 1999.

10. LANGFORD, M. Fotografia Básica. Lisboa: Dinalivro, 1986. p.165.

11. MONTE, A. C. A qualidade dos suportes da informação, uma visão arquivística. 2003. Dissertação de Mestrado - Universidade Federal de Santa Maria, 2003.

12. PAES, M. L. Arquivo: teoria e prática. $5^{\text {a }}$ reimp. Rio de Janeiro: FGV, 2005.

13. PAVÃO, L. Conservação de Coleções de Fotografia. Lisboa: Dinalivro. 1997.

14. ROSE, C. Fotografia digital: aprenda em 14 dias. Rio de Janeiro: Campus, 1998.

15. SCHÄFER, M. B.; FLORES, D. Documentos Digitais: características dos suportes de armazenamento para documentos permanentes. In: Congresso de Arquivologia do Mercosul, 9, 2011, San Lorenzo. Anais... San Lorenzo: Faculdade Politécnica - Universidade Nacional de Assunção, 2011.

16. SCHÄFER, M. B. Digitalização de documentos: implicações no acesso às informações arquivísticas. 2013. Dissertação (Curso de Mestrado Profissionalizante do Programa de Pósgraduação em Patrimônio Cultural) Universidade Federal de Santa Maria, Santa Maria, 2013. 